\title{
ADOLESCENT PREGNANCY AND FAMILY WELFARE EXPENDITURE IN INDIA: A STATE-LEVEL ANALYSIS USING NATIONAL FAMILY HEALTH SURVEY DATA
}

\author{
Rimon Saha ${ }^{1,2}$ and Sanchita Mukherjee ${ }^{3}$ \\ ${ }^{1}$ Doctoral fellow at Centre for development studies, Thiruvananthapuram, Kerala, India and \\ ${ }^{2}$ Assistant Professor at Triveni Devi Bhalotia College, Raniganj, West Bengal, India \\ ${ }^{3}$ Doctoral candidate at Centre for development studies, Thiruvananthapuram, Kerala, India
}

DOI: 10.46609/IJSSER.2020.v05i10.027 URL: https://doi.org/10.46609/IJSSER.2020.v05i10.027

\begin{abstract}
Background: Rising adolescent Pregnancy has been considered as an emerging serious concern all over the world, especially in case of developing countries. Preventing births very early in a woman's life is an important measure to improve maternal health and reduce infant mortality. This paper examines the problem adolescent pregnancy in India and provides an overview of present situation.
\end{abstract}

Objectives: The paper analyzes interstate disparities and disparities across socio-economic groups in the adolescent birth rates (ABR) and examines the response of adolescent birth rate to state government family welfare expenditure in India during 2005-06 and 2015-16.

Methods: Data from Reserve Bank of India (RBI) Bulletin, National Family Health Survey for the year 2005-06 (NFHS-3) and 2015-16 (NFHS-4) are used to compute and compare adolescent birth rates in India. Expenditure elasticity of $A B R$ and position analysis is used to examine the effect of government family welfare expenditure on ABR

Results: ABR is negatively correlated with government family welfare expenditure. The impact of government family welfare expenditure on ABR is most prominent for the states of Bihar, Haryana, Karnataka and Odhisa. During the decade, Uttar Pradesh has shown remarkable improvement, whereas West Bengal is the worst performer.

Conclusion: ABR being a progress indicator of Sustainable Development Goal-3, results show that greater investment on family welfare by the States would result in more effective reduction of ABR to its 2030 SDG target. 


\section{International Journal of Social Science and Economic Research}

ISSN: $2455-8834$

Volume:05, Issue:10 "October 2020"

Keywords: Sustainable development goals, Adolescent birth rate, Family welfare expenditure

\section{INTRODUCTION}

In recent times, adolescent or teenage pregnancy has evolved to be a serious health concern worldwide, especially for the developing countries such as India. Reducing adolescent pregnancy is considered as one of the important agendas among 17 Sustainable Development Goals (SDGs) set out by United Nations (UN) development agenda. It is considered as one of the progress indicators for SDG 3, which laid out the goal related to 'ensure healthy lives and promote wellbeing for all at all ages' by the year 2030 .

There is substantial agreement in the literature that women who become pregnant and give birth very early in their reproductive lives are subject to higher risks of complications or even death during pregnancy and birth and their children are also more vulnerable (Sudhir et. al. 2015; Rachakonda et. al. 2014). Such pregnancies are dangerous for mother, child as well as community as a whole. Furthermore, women having children at earlier age leads to school dropout, curtailment of opportunities and financial dependence (Turner et. al, 1990;Lounds, 2009).

Although women aged 10-19 years account for $11.0 \%$ of all births worldwide, they account for $23.0 \%$ of the overall burden of disease due to pregnancy and childbirth (NFHS-3 Report). Approximately 16 million girls aged 15 to 19 years and about two million girls under the age of 15 contribute to birth during adolescent age, worldwide. However, around $95 \%$ of the total adolescent birth takes place in low and middle-income countries (WHO, 2015; Ghose and John, 2017). A study by Neal et. al (2018) on 64 demographic and Health Surveys collected between 2005 and 2015 from 45 countries, found risk of neonatal mortality to be high among adolescent mothers (aged below 20) and found such pattern to be pronounced in sub-Saharan Africa and South and South-East Asia. In India, teenage pregnancy poses a serious public-health problem, although the national policy of the Government of India advocates the minimum legal age of marriage for girls to be 18 years. Results from National Family Health Survey (NFHS)-3 data showed that $16 \%$ of women, aged 15-19 years, have already started childbearing. However, this proportion is varied across Indian states (Parsuraman et. al 2009, NFHS-3 Report). The countries with high rates of child marriage and early child-bearing are also the ones facing the major issues with high adolescent birth rates and maternal mortality rates (Loaiza and Liang, 2013).

To reduce adolescent pregnancy effectively it is essential that efforts for adolescent-responsive family planning and services have to be far more serious.Jones and Marshall (2017) suggests, though improving access to female contraceptives among adolescent girls'would be a costeffective step, but alone it cannot prove to be effective. Hence funding and policy prioritisation 


\section{International Journal of Social Science and Economic Research}

ISSN: $2455-8834$

Volume:05, Issue:10 "October 2020"

for tackling adolescent pregnancy is urgently needed. Effort and investment have to be made towards changing gender norms, prevent child marriages as well as schooling of girl child. This calls for targeted interventions to support girls with an early initiation into marital relationships and child-bearing. Ready access to sexual and reproductive health information and programmes that provide family planning, maternal health services, and HIV prevention and treatment is an important requirement by the married adolescent girls. To carry out these programmes, state family welfare expenditure plays a crucial role. The positive impact of social and public health spending in health outcomes including controlling adolescent birth rate, maternal mortality and infant mortality etc. are being well documented in literature. Sipsma et al. (2017) finds the states with higher spending on social and public health service are associated with statistically substantial lower teenage birth rate in United States between 2005 and 2009.

In India, Government expenditure has been directed to some of the schemes to control Adolescent birth rate and aid adolescent health. 'Kishori Shakti Yojna', 'Balika Samridhi Yojna' and 'SABLA' are some of the important programmes, targeted to increase the age of marriage of girls apart from improving their nutrition and health status by promoting awareness about health, hygiene, nutrition, reproductive/sexual health (Maliye and Garg, 2017). 'Adolescent Reproductive Sexual Health' Program is another such programme targeted towards married/unmarried girls and boys under reproductive andchild health providing for adolescent friendly health services, personal care and counseling regarding SIT, contraceptives, management of sexual violence as well as substance abuse (GOI, 2006). It is therefore essential to analyze the response of ABR to state family welfare expenditure.

In this paper we analyze the issue of adolescent pregnancy across various socio-economic groups and examine the efficiency of state family welfare spending to reduce ABR across Indian states.

\section{MATERIALS AND METHODS}

\section{Data and Methodology}

This study uses data from third and fourth round of National Family Health Survey (NFHS henceforth), India. NFHS-3 was conducted during 2005-06 while NFHS-4 data has been compiled for2015-16. The National Family Health Survey (NFHS) is a large-scale, multi-round survey conducted on representative sample of households throughout India. The survey provides state and national information for India on various socio-demographic and health indicators.

For the analysis, ABR has been computed for 15 major states in India across two time periods and various well-defined social groups such as religion, region, caste etc.; also into population sub-groups with combined characteristics such as urban-scheduled caste, rural-scheduled caste, etc. Interstate comparison of $\mathrm{ABR}$ has been done by considering the lowest ABR state as the 
International Journal of Social Science and Economic Research

ISSN: 2455-8834

Volume:05, Issue:10 "October 2020"

reference for both the time periods. Further an estimation ofABR level in 2030 forsuch groups has been computed by extrapolating the growth rate between two periods. The estimated rate of ABR 2030 has been compared to the India-SDG target for 2030.

Next, average per capita state expenditure for 10 years for two time periods corresponding to NFHS surveys (1995-2004 expenditure data forNFHS-3, 2005-06 outcome and 2005-2014 expenditure data forNFHS-4, 2015-16 outcomes), has been obtained from Reserve Bank of India (RBI) database. Using this data family welfare expenditure elasticity of the outcome ABR across states has been computed fortwo-time points. The population considered for per-capita calculation is considered to be the targeted population i.e. 15-49 years of females only. To measure the efficiency of spending, position analysis using the quadratic diagram has also been attempted.

\section{RESULTS}

\section{Adolescent Birth Rate in Indian States}

Table 1 presents and compares ABR across various states. ABR1 is calculated using NFHS-3 data, while ABR2 is calculated using NFHS-4 data. ABR progress has been computed by subtracting ABR1 from ABR2. Growth rate of ABR and estimation of ABR for 2030 has been computed as follows:

$$
A B R G \text { rowthRate }=\left(\left(\frac{A B R 2}{A B R 1}\right)^{1 / 10}-1\right) * 100
$$

\section{$A B R 2030 E s t .=A B R 2 *(1+(A B R G \text { rowthRate } / 100))^{15}$}

It can be seen from table 1 that, West Bengal, Bihar, Andhra Pradesh, Karnataka and Assam are some of the states with highest ABR during NFHS3. During NFHS4, though Andhra Pradesh and Karnataka have shown subsequent reduction, however West Bengal, Assam and Bihar still continues to be the states with higher ABR. From ABR Progress column it can be interpreted that, ABR has reduced for all states. Reduction has been highest in case of Bihar, Uttar Pradesh, Rajasthan and Karnataka. Negative sign of growth rate shows declining trend in ABR over the years. The decline rate has been highest in case of Uttar Pradesh and lowest for Assam and West Bengal. Extrapolation result of ABR for 2030, estimates highest ABR for West Bengal and Bihar, while Uttar Pradesh, Punjab and Kerala would be the states with lowest ABR. 
International Journal of Social Science and Economic Research

ISSN: 2455-8834

Volume:05, Issue:10 "October 2020"

Table 1: Adolescent Birth Rate, Growth Rate and Estimated ABR in 2030 in Indian States

\begin{tabular}{|l|l|l|l|l|l|}
\hline State & ABR1 & ABR2 & ABR Progress & $\begin{array}{l}\text { ABR Growth } \\
\text { Rate }\end{array}$ & ABR 2030 Est. \\
\hline Andhra Pradesh & 18.1 & 11.8 & 6.3 & -4.19 & 6.21 \\
\hline Assam & 16.4 & 13.6 & 2.8 & -1.85 & 10.27 \\
\hline Bihar & 25 & 12.2 & 12.8 & -6.92 & 4.16 \\
\hline Gujarat & 12.7 & 6.5 & 6.2 & -6.48 & 2.38 \\
\hline Haryana & 12.1 & 5.9 & 6.2 & -6.93 & 2.01 \\
\hline Karnataka & 17 & 7.8 & 9.2 & -7.50 & 2.42 \\
\hline Kerala & 5.8 & 3 & 2.8 & -6.38 & 1.12 \\
\hline $\begin{array}{l}\text { Madhya } \\
\text { Pradesh }\end{array}$ & 13.6 & 7.3 & 6.3 & -6.03 & 2.87 \\
\hline Maharashtra & 13.8 & 8.3 & & & \\
\hline Odisha & 14.5 & 7.6 & 6.5 & -4.96 & 3.87 \\
\hline Punjab & 5.5 & 2.6 & 2.9 & -6.26 & 2.88 \\
\hline Rajasthan & 16 & 6.3 & 9.7 & -7.22 & 0.85 \\
\hline Tamil Nadu & 7.7 & 5 & 2.7 & -8.90 & 1.56 \\
\hline Uttar Pradesh & 14.3 & 3.8 & 10.5 & -12.41 & 2.62 \\
\hline West Bengal & 25.3 & 18.3 & 7 & -3.19 & 0.52 \\
\hline
\end{tabular}

Note: ABR1 refers to adolescent birth rates in 2005-06 and ABR2 refers to adolescent birth rates in 2015-16

Source: Author's calculations using NFHS 3 and NFHS 4 data 
International Journal of Social Science and Economic Research

ISSN: 2455-8834

Volume:05, Issue:10 "October 2020"

Figure 1: Inter-state comparison of Adolescent Birth Rate in India during 2005-06 and 2015-16 (Picture format)
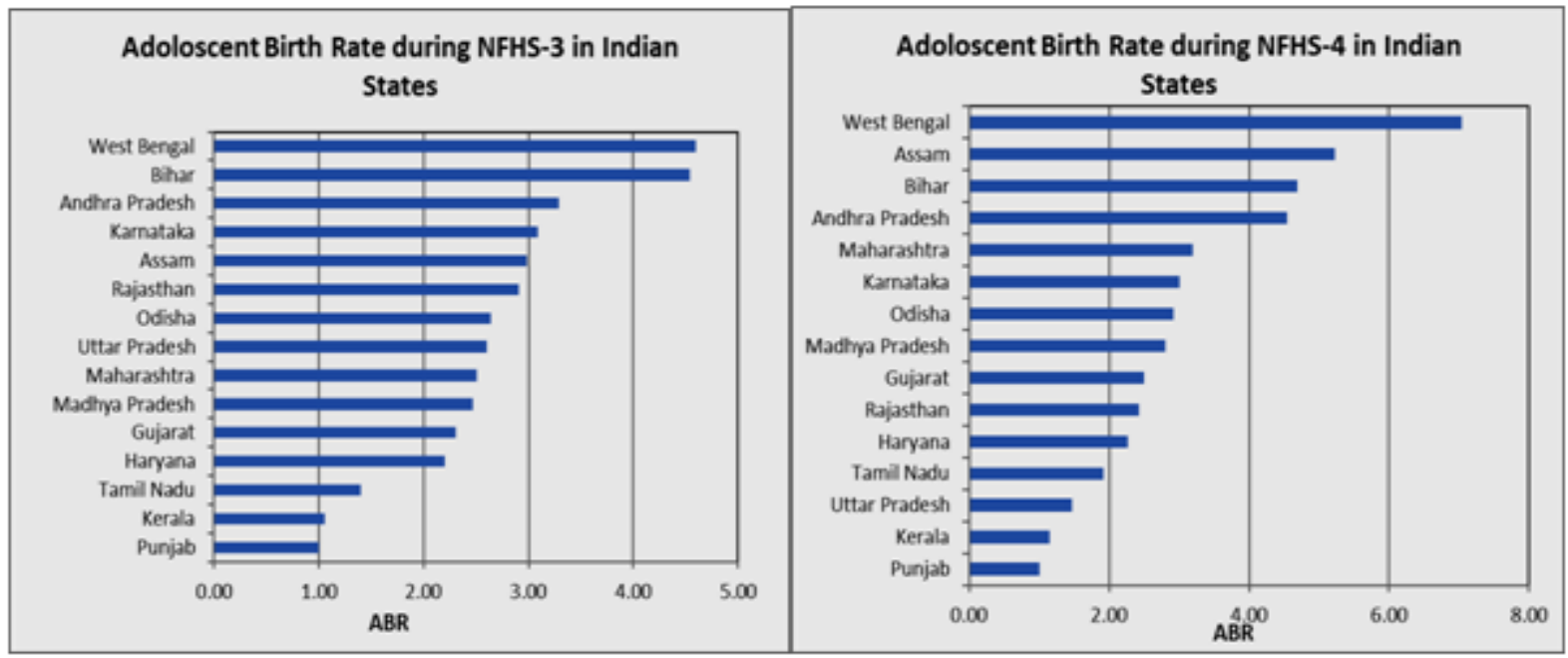

Source: Author's calculations using NFHS 3 and NFHS 4 data

To compare the ABR values across states in each time point we locate the lowest ABR state and then divide all the other value by the lowest value, this in turn gives us the value of thelowest ABR state as one and others greater than one. This exercise shows how far or near the other states is situated with respect to lowest ABR states and provides us with a clearer comparison across states in each time point. From the above figure 1 we observe that ABR of West Bengal and Bihar is four times more than Punjab (the state having lowest ABR) in 2005-06. In that year apart from Kerala and Tamil Nadu all other states have two times more ABR compared to Punjab and certain states like Assam, Karnataka and Andhra Pradesh almost has triple rates compared to the lowest ABR state. The comparative picture worsens in 2015-16 for the states West Bengal, Bihar, Andhra Pradesh and Assam as these states have four times more than ABR compared to Punjab still the lowest ABR states and for West Bengal the rate is six times worse than Punjab.

\section{Adolescent Birth Rate among Socio-demographic Groups}

A similar exercise has been performed to compare ABR across socio-demographic groups, namely Caste, Region, Residence and Religion. Growth rate of $\mathrm{ABR}$ and estimation of $\mathrm{ABR}$ for 2030 has been also computed for these groups. Results are presented in Table 2. 
International Journal of Social Science and Economic Research

ISSN: 2455-8834

Volume:05, Issue:10 "October 2020"

Table 2: Adolescent Birth Rate, Growth Rate and Estimated ABR in 2030 by sociodemographic groups in India

\begin{tabular}{|l|l|l|l|l|l|}
\hline Caste & ABR1 & ABR2 & ABR Progress & $\begin{array}{l}\text { ABR Growth } \\
\text { Rate }\end{array}$ & ABR 2030 Est. \\
\hline SC & 11.3 & 9.1 & 2.2 & -2.2 & 6.5 \\
\hline ST & 10.3 & 11.8 & -1.5 & 1.4 & 14.5 \\
\hline OBC & 12.8 & 10.5 & 2.3 & -2.0 & 7.8 \\
\hline Others & 12.3 & 7.8 & 4.6 & -4.5 & 3.9 \\
\hline Total & 12.0 & 9.8 & 2.2 & -2.0 & 7.2 \\
\hline Region & ABR1 & $\mathbf{A B R 2}$ & ABR Progress & $\begin{array}{l}\text { ABR Growth } \\
\text { Rate }\end{array}$ & ABR 2030 Est. \\
\hline North & 14.3 & 9.9 & 4.4 & -3.6 & 5.7 \\
\hline Central & 13.3 & 11.2 & 2.1 & -1.7 & 8.6 \\
\hline East & 8.6 & 8.5 & 0.1 & -0.1 & 8.4 \\
\hline North-East & 14.6 & 4.6 & 10.0 & -10.8 & 0.8 \\
\hline West & 14.2 & 12.6 & 1.6 & -1.2 & 10.5 \\
\hline South & 8.0 & 9.5 & -1.6 & 1.8 & 12.5 \\
\hline Total & 11.9 & 9.5 & 2.4 & -2.2 & 6.8 \\
\hline Residence & ABR1 & $\mathbf{A B R 2}$ & ABR Progress & $\begin{array}{l}\text { ABR Growth } \\
\text { Rate }\end{array}$ & ABR 2030 Est. \\
\hline Urban & 12.2 & 9.9 & 2.3 & -2.1 & 7.2 \\
\hline Rural & 11.9 & 9.4 & 2.4 & -2.3 & 6.7 \\
\hline Total & 11.9 & 9.5 & 2.4 & -2.2 & 6.8 \\
\hline Religion & ABR1 & $\mathbf{A B R 2}$ & ABR Progress & $\begin{array}{l}\text { ABR Growth } \\
\text { Rate }\end{array}$ & ABR 2030 Est. \\
\hline Hindu & 11.6 & 9.8 & 1.8 & -1.7 & 7.6 \\
\hline Muslim & 14.4 & 8.7 & 5.8 & -5.0 & 4.0 \\
\hline $\begin{array}{l}\text { Other } \\
\text { Religion }\end{array}$ & 7.2 & 8.1 & -0.9 & 1.2 & 9.8 \\
\hline Total & 11.9 & 9.5 & 2.4 & -2.2 & 6.8 \\
\hline
\end{tabular}

Note: $A B R 1$ refers to adolescent birth rates in 2005-06 and ABR2 refers to adolescent birth rates in 2015-16

Source: Author's calculations using NFHS 3 and NFHS 4 data

As it can be construed from the above table, among all castes ST is worst performer in terms of ABR. Except for ST, ABR has shown declining trend over the period of NFHS-3 and NFHS-4. The estimation shows ABR among ST will be highest in 2030 at $14.1 \%$ among all castes, while 'Others' will be at lowest of 3.9\%. In case of religions, 'Muslim' shows higher rate of decline in 
International Journal of Social Science and Economic Research

ISSN: 2455-8834

Volume:05, Issue:10 "October 2020"

ABR compared to 'Hindu'. For 'Muslim' ABR has declined from $14.4 \%$ in NFHS-3 to $8.7 \%$ in NFHS-4. Estimated ABR for 'Hindu' in 2030 is $7.6 \%$.

Among regions 'West' has the highest ABR in NFHS-4, followed by Central Region. North-East has shown the highest decline in ABR from being the region with highest ABR (14.6\%) during NFHS-3 to be the region with the lowest ABR (4.6\%) during NFHS-4.Southern region though had the lowest ABR in NFHS-3, has shown increasing trend and is predicted to have ABR of $12.5 \%$ in 2030 , followed by Western region at $10.5 \%$. North-East with the highest declining rate of $\mathrm{ABR}$ is estimated to be only of $0.8 \%$ in 2030. ABR shows overall declining trend for both Urban and Rural areas. In 2030 Urban is estimated to have slightly higher ABR (7.2\%) compared to that of rural region $(6.7 \%)$.

Since the study also focuses on multi deprivation aspect, we further present few tables to look at select results from some of the combined socio-economic categories. Table 3 presents the results of ABR across sub groups combining religion and caste, while Table 4 charts the change in ABR across combined sub-groups of residence and religion characteristics, and estimates the ABR for these groups in 2030 .

Table-3: Adolescent Birth Rate, Growth Rate and Estimated ABR in 2030 by combining residence and caste in India

\begin{tabular}{|l|l|l|l|l|l|}
\hline $\begin{array}{l}\text { CASTE and } \\
\text { RESIDENCE }\end{array}$ & $\begin{array}{l}\text { ABR } \\
\mathbf{1}\end{array}$ & $\begin{array}{l}\text { ABR } \\
\mathbf{2}\end{array}$ & $\begin{array}{l}\text { ABR } \\
\text { Progress }\end{array}$ & $\begin{array}{l}\text { ABR Growth } \\
\text { Rate }\end{array}$ & $\begin{array}{l}\text { ABR 2030 } \\
\text { Est. }\end{array}$ \\
\hline Urban-SC & 15.4 & 5.8 & 9.6 & -9.3 & 1.3 \\
\hline Urban-ST & 13.4 & 19.1 & -5.7 & 3.6 & 32.7 \\
\hline Urban-OBC & 13.4 & 11.2 & 2.2 & -1.8 & 8.5 \\
\hline Urban-Others & 8.6 & 10.4 & -1.9 & 2.0 & 14.0 \\
\hline Rural-SC & 10.6 & 9.9 & 0.7 & -0.7 & 8.9 \\
\hline Rural-ST & 10.0 & 10.9 & -1.0 & 0.9 & 12.5 \\
\hline Rural-OBC & 12.7 & 10.4 & 2.4 & -2.1 & 7.6 \\
\hline Rural-Others & 13.6 & 6.8 & 6.9 & -6.8 & 2.4 \\
\hline
\end{tabular}

Note: ABR1 refers to adolescent birth rates in 2005-06 and ABR2 refers to adolescent birth rates in 2015-16

Source: Author's calculations using NFHS 3 and NFHS 4 data

It can be interpreted from table 3 that in 2015-16 urban area, ABR is highest among ST with a growth rate of about $3.6 \%$ from NFHS-3 to NFHS-4. ABR among Urban ST is estimated to be 
$32.7 \%$ in 2030. ABR among ST population is the highest among rural population as well; however trend of growth is in a lower trajectory. It is estimated that ABR among rural ST population will be about $12.5 \%$ in 2030 . Among all these groups, ABR among Urban SC population is the lowest and has declined from $15.4 \%$ in NFHS-3 to 5.8\% in NFHS-4. From the table one interesting observation can be made that when caste is combined with region, the caste wise performance of the indicator becomes specific to region. For example, Rural-Others has the lowest ABR but for Urban region it's the SC group, Again, Rural- ST is performing better than Urban-Others in NFHS-4 period. So, with this we can observe a region-specific caste performance.

Table-4: Adolescent Birth Rate, Growth Rate and Estimated ABR in 2030 by combining residence and religion in India

\begin{tabular}{|l|l|l|l|l|l|}
\hline $\begin{array}{l}\text { RELIGION and } \\
\text { RESIDENCE }\end{array}$ & $\begin{array}{l}\text { ABR } \\
\mathbf{1}\end{array}$ & $\begin{array}{l}\text { ABR } \\
\mathbf{2}\end{array}$ & $\begin{array}{l}\text { ABR } \\
\text { Progress }\end{array}$ & $\begin{array}{l}\text { ABR Growth } \\
\text { Rate }\end{array}$ & $\begin{array}{l}\text { ABR 2030 } \\
\text { Est. }\end{array}$ \\
\hline Urban-Hindu & 12.1 & 9.6 & 2.5 & -2.3 & 6.8 \\
\hline Urban-Muslim & 13.2 & 11.9 & 1.3 & -1.0 & 10.2 \\
\hline Urban-Other religion & 8.5 & 1.8 & 6.7 & -14.4 & 0.2 \\
\hline Rural-Hindu & 11.5 & 9.9 & 1.7 & -1.5 & 7.8 \\
\hline Rural-Muslim & 14.8 & 7.5 & 7.3 & -6.5 & 2.7 \\
\hline Rural-Other religion & 6.5 & 9.4 & -2.9 & 3.7 & 16.4 \\
\hline
\end{tabular}

Note: ABR1 refers to adolescent birth rates in 2005-06 and ABR2 refers to adolescent birth rates in 2015-16

Source: Author's calculations using NFHS 3 and NFHS 4 data

Above table depicts the decreasing trend in ABR when compared between NFHS-3 and NFHS-4 among all the groups, except 'others' in rural area. Declining trend in ABR is more prominent among 'Other religion' in rural area, while such trend is observed among 'Muslims' in rural area as well. Previously although we found that in 2015-16 urban region has higher ABR compared to rural (table 2) but if we notice table 4 Rural-Hindu has higher ABR than Urban-Hindu, again, Rural-Muslim has lower ABR compared to Urban-Hindu. So region adds to a new dimension in the interactions of the category religion. 
International Journal of Social Science and Economic Research

ISSN: 2455-8834

Volume:05, Issue:10 "October 2020"

\section{Family Welfare Expenditure Elasticity and ABR}

Table 5 compares ABR1 and ABR2 with corresponding Average Family Welfare expenditure (Avg. FWEXP, henceforth) for the states in the same time period. Avg. FWEXP1 represents average family welfare expenditure for the period 1995-2004, while Avg. FWEXP2 is for period of 2005-2014. It can be seen that Rajasthan, Tamil Nadu and Andhra Pradesh are some of the states with highest family welfare expenditure during 2005-2014 as well as in 1995-2004. In 2005-14, Uttar Pradesh emerged as one of states with high family welfare expenditure, though it had a much lower expenditure in 1995-2004.

Expenditure Elasticity of ABR has been calculated for each state using the formula below:

$$
\text { EXPELASTICITY }=\frac{(\text { ABR2 }- \text { ABR1 }) / \text { ABR1 }}{(\text { Avg. FWEXP2 }- \text { Avg. FWEXP1 }) / \text { Avg. FWEXP1 }}
$$

Negative sign confirms that the relationship between Family Welfare Expenditure and Adolescent Birth Rate is inversely related to each other. Hence, increase in Avg. FWEXP caused decrease in ABR. The value of Expenditure Elasticity of ABR represents responsiveness in ABR when the level of Avg. FWEXP changes. High elasticity indicates ABR is sensitivity to change in Avg. FWEXP, while lower value indicates little sensitivity of ABR to change in expenditure.

Results show Bihar has the highest Expenditure elasticity of ABR, followed by Haryana, Karnataka and Odisha and the state with lowest elasticity is Tamil Nadu followed by Assam.

Table 5: Adolescent Birth Rate, Average Family Welfare Expenditure and Expenditure Elasticity of ABR in Indian States

\begin{tabular}{|l|l|l|l|l|l|}
\hline STATE & ABR1 & ABR2 & Avg. FWEXP1 & Avg. FWEXP2 & $\begin{array}{l}\text { EXP } \\
\text { ELASTICITY }\end{array}$ \\
\hline Andhra Pradesh & 18.10 & 11.80 & 116.10 & 272.07 & -0.26 \\
\hline Assam & 16.40 & 13.60 & 79.83 & 171.83 & -0.15 \\
\hline Bihar & 25.00 & 12.20 & 98.85 & 112.65 & -3.67 \\
\hline Gujarat & 12.70 & 6.50 & 85.50 & 235.33 & -0.28 \\
\hline Haryana & 12.10 & 5.90 & 89.92 & 152.72 & -0.73 \\
\hline Karnataka & 17.00 & 7.80 & 111.31 & 222.93 & -0.54 \\
\hline Kerala & 5.80 & 3.00 & 100.07 & 268.25 & -0.29 \\
\hline $\begin{array}{l}\text { Madhya } \\
\text { Pradesh }\end{array}$ & 13.60 & 7.30 & 69.74 & 137.91 & -0.47 \\
\hline
\end{tabular}


International Journal of Social Science and Economic Research

ISSN: 2455-8834

Volume:05, Issue:10 "October 2020"

\begin{tabular}{|l|l|l|l|l|l|}
\hline Maharashtra & 13.80 & 8.30 & 59.89 & 148.31 & -0.27 \\
\hline Odisha & 14.50 & 7.60 & 77.91 & 147.98 & -0.53 \\
\hline Punjab & 5.50 & 2.60 & 72.34 & 165.31 & -0.41 \\
\hline Rajasthan & 16.00 & 6.30 & 129.13 & 393.89 & -0.30 \\
\hline Tamil Nadu & 7.70 & 5.00 & 104.35 & 358.52 & -0.14 \\
\hline Uttar Pradesh & 14.30 & 3.80 & 79.30 & 339.58 & -0.22 \\
\hline West Bengal & 25.30 & 18.30 & 72.09 & 149.02 & -0.26 \\
\hline
\end{tabular}

Note: ABR1 refers to adolescent birth rates in 2005-06 and ABR2 refers to adolescent birth rates in 2015-16

Source: Author's calculations using NFHS 3 and NFHS 4 data

\section{Position Analysis}

Position analysis has been performed to understand the relative efficiency among states. The analysis has been represented using quadratic diagrams below. For the position analysis we consider two variables such as state family expenditure and ABR value. For each variable we located the 'Best performing state'.We consider the state with highest stateexpenditure and lowest value of ABR to be the 'Best performing state'. We have positioned other states according to the 'Best performing state'. For the position value, each state's value is divided by the value of the 'Best performing state', which in turn gives us the value of the 'Best performing state' as one and others lesser than one. Then the combination of the position value of the two variables for each state is plotted in the quadratic diagrams in figure 2.

Figure 2 presents relative position of ABR and State Family Welfare Expenditure. The diagram shows in the period 1995-2004, Tamil Nadu, Kerala, and Punjab are some of the overall better performing states with lower level of $A B R$ as well as higher level of State Family Welfare Expenditure. In the period 2005-2014, along with Kerala and Tamil Nadu, Uttar Pradesh had also performed much better in terms of both indicators. West Bengal, Bihar, Odisha, Maharashtra, Madhya Pradesh, Assam are some of the states with higher ABR and low State Family Welfare Expenditure, in the period 2005-2014. 
International Journal of Social Science and Economic Research

ISSN: 2455-8834

Volume:05, Issue:10 "October 2020"

Figure 2: Relative positions of states with respect to ABR and State Family Welfare Expenditure during 2005-06 and 2015-16 (Picture format)

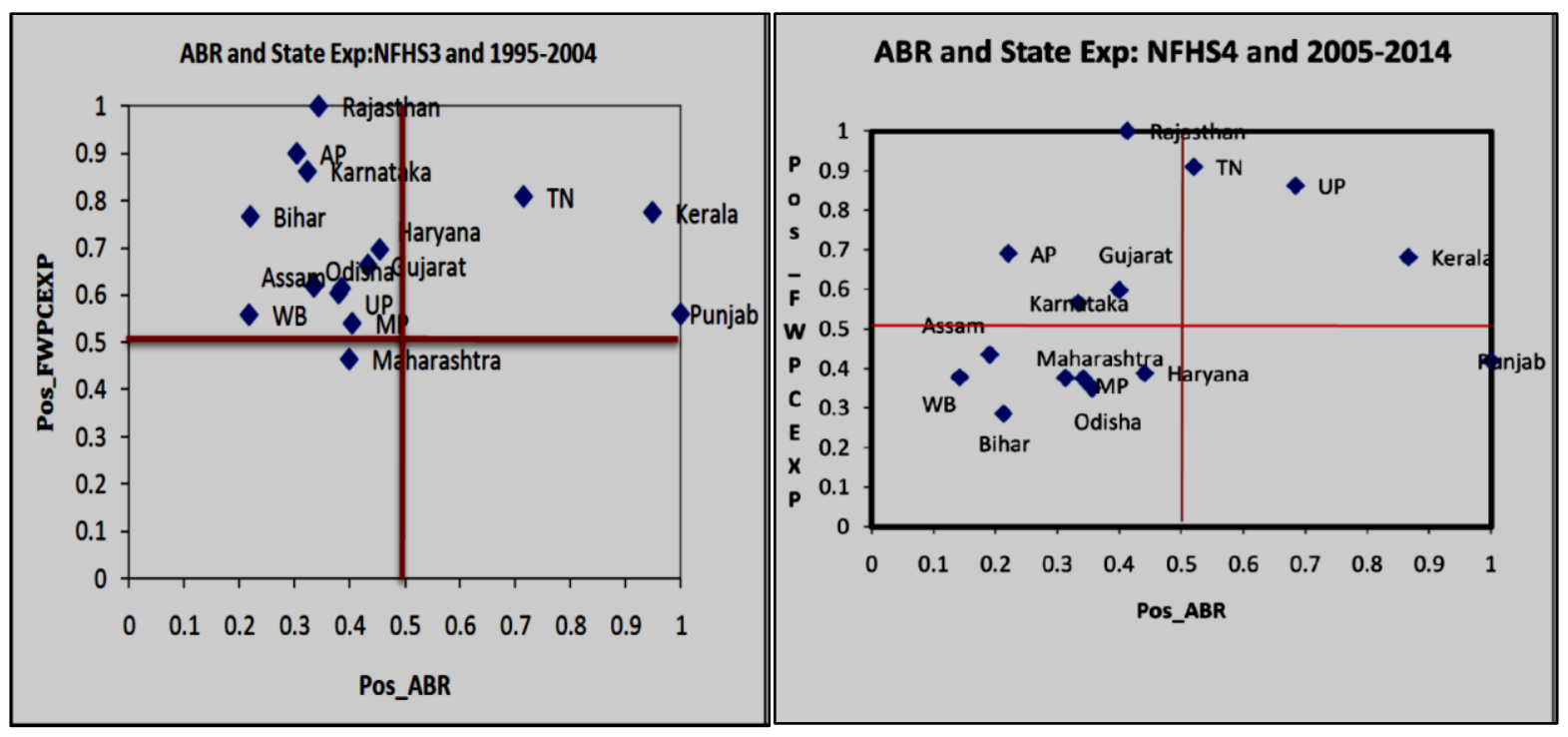

Source: Author's calculations using NFHS 3 and NFHS 4 data

\section{DISCUSSION}

The current study compared ABR indicators during the time period of NFHS-3 and NFHS-4. It is evident that, though ABR has shown declining trend over the years, however some states fared better than others. West Bengal remained to be the state with highest ABR across the time period. Bihar has showed some improvement, but still continued to be one of stateswithhigh ABR. Assam has not made much progress and became the state with second highest ABR during NFHS-4. Uttar Pradesh has surprisingly shown a very high rate of decline in ABR over the time period and it is expected to be the state with lowest ABR in 2030. Punjab, Kerala and has remained to be bottom states with lowest ABR across the time period. When ABR is compared across regions, southern region shows and increasing trend of $A B R$, and estimated to be substantially high by 2030. All other region shows declining trend, with Northern region being the lowest. Among caste groups, ST is found to have a higher ABR and estimated to be much higher by 2030. When compared among religion, Muslim shows a prominent declining trend of ABR over the period. Difference in ABR trend in urban and rural didn't seem to be varying highly in either period. Further, combining residence caste and religion highlights the regionspecific characteristics of the same. It draws attention to the groups with double deprivations such as Urban-ST of the residence-caste sub group and Urban-Muslims of the residence-religion sub group. Urban region in general have higher ABR compared to rural but if one resides in 
International Journal of Social Science and Economic Research

ISSN: 2455-8834

Volume:05, Issue:10 "October 2020"

Urban region and also belongs to ST category her deprivation becomes two-fold. Similarly, Urban-Muslims also experience double deprivations.

In the attempt to reduce the adolescent pregnancy (apart from other objectives of Family welfare) state allocates certain amount of resources on family welfare every year. Rajasthan, Tamil Nadu, Andhra Pradesh, Kerala are some of the states with highest family welfare expenditure during 2005-2014 as well as in 1995-2004. In 2005-14, Uttar Pradesh also emerged as one of states with high family welfare expenditure, compared to its level in 1995-2004. But the responsiveness of such expenditure towards the reduction of ABR is found to be highest in Bihar followed by Haryana, Karnataka and Odisha.

Position analysis reveals that states with higher family welfare expenditure has shown declining trend of ABR over the period. Uttar Pradesh is an example state where ABR shows a steep declining rate over the period and family welfare expenditure has risen considerably over the years, while in contrast West Bengal remained to be a state with high ABR and one of the states with lowest Family Welfare Expenditure during both time periods. Other states with higher welfare expenditure such as Kerala, Tamil Nadu, Andhra Pradesh emerges to be better performer in terms of ABR. In summary, it can be said that greater investment on family welfare appears to have positive influence in lowering adolescent birth rate in India.

\section{REFERENCES}

1. Bradley, E. H., Elkins, B. R., Herrin, J., and Elbel, B. (2011). Health and social services expenditures: associations with health outcomes. BMJ Qual saf, 20(10), 826-831.

2. Ghose S, John LB. Adolescent pregnancy: an overview. Int J Reprod Contracept Obstet Gynecol. 2017;6:4197-203.

3. Jones, N., and Presler-Marshall, E. (2017). Family planning: the adolescent imperative (Policy Briefing). GAGE, ODI, UK

4. Loaiza, E., and Liang, M. (2013). Adolescent pregnancy: A review of the evidence Report. UNFPA, New York

5. Lounds Taylor, J. (2009). Midlife impacts of adolescent parenthood. Journal of family issues, 30(4), 484-510.

6. Maliye, C., and Garg, B. S. (2017). Adolescent health and adolescent health programs in India. Journal of Mahatma Gandhi Institute of Medical Sciences, 22(2), 78. 


\section{International Journal of Social Science and Economic Research}

ISSN: 2455-8834

Volume:05, Issue:10 "October 2020"

7. Neal, S., Channon, A. A., and Chintsanya, J. (2018). The impact of young maternal age at birth on neonatal mortality: Evidence from 45 low- and middle-income countries. PloS one, 13(5), e0195731.

8. Rachakonda, L., Rawate, S., \& Shiradkar, S. (2014). Teenage pregnancy. International Journal of Current Medicial and Applied Sciences, 4(2), 2059-63.

9. Sipsma, H. L., Canavan, M., Gilliam, M., and Bradley, E. (2017). Impact of social service and public health spending on teenage birth rates across the USA: an ecological study. BMJ open, 7(5), e013601.

10. Sudhir, A., Rasquinha, V. C., and Rao, S. B. (2015). Outcome of pregnancy in adolescent age group. Journal of Evolution of Medical and Dental Sciences, 4(43), 7483-7489.

11. Sulabha Parasuraman, Sunita Kishor, Shri Kant Singh, and Y. Vaidehi. 2009. AProfile of Youth in India. National Family Health Survey (NFHS-3), India, 2005-06. Mumbai:International Institute for Population Sciences; Calverton, Maryland, USA: ICF Macro.

12. Turner, R. J., Grindstaff, C. F., and Phillips, N. (1990). Social support and outcome in teenage pregnancy. Journal of health and social behavior, 43-57.

13. World Health Organization, Regional Office for South-East Asia. (2015). Adolescent pregnancy situation in South-East Asia Region. WHO Regional Office for South-East Asia.

14. World Health Organization. (2003).Towards adulthood: exploring the sexual and reproductive health of adolescents in South Asia. Geneva: World Health Organization, 244 p.

15. World Health Organization. (2005). Nutrition in adolescence: issues and challenges for the health sector: issues in adolescent health and development. World Health Organization, Geneva. 